\title{
Prediction on Human Resource of Real Estate Based on the Principle of Metabolism GM(1,1) Model
}

\author{
Guomin Fang 1, 2 \\ 1. College of Applied Mathematics \\ Chengdu University of Information Technology
}

\begin{abstract}
Aim to the two problem of traditional grayforecast model GM(1,1), we proposed an improved $\operatorname{GM}(1,1)$ model based on the principles of metabolism, and introduced its application in prediction on human resource of real estate. The improved idea is to consider simultaneously the following two factors: the selection of the initial conditions and the adjustment methods of model parameter. According to real estate practitioners nationwide data from 1993 to 2012, we predicted the demand of workers in 2013- 2015 by using the improved $\operatorname{GM}(1,1)$ model, the prediction precision grade of model is 1 (Excellent) $(\mathrm{C}=\mathbf{0 . 0 1 1}<0.35, \mathrm{p}=1>0.95)$. The demand for human resources of real estate industry in 2013-2015 are about 29431 thousands, 3186.5 thousands, and 3445 thousands, respectively, which provide a reference for government or corporate macro-decisions.
\end{abstract}

Keywords-prediction; human resource; GM(1,1) model; real estate industry; metabolism

\section{INTRODUCTION}

Human resource planning is a necessary link in the human resource management, it must be based on the prediction based on supply and demand on the accurate personnel. Predicting the demand of human resource is a technical work, its accuracy directly determines the success or failure of the plan. It is the most difficult and also the most crucial step in the entire human resources planning. Existing human resource quantitative prediction method mainly: time series models, regression models, econometric model, and the state transition equation model. However, these methods are generally required to have enough samples, sufficient data, also need to meet the typical probability distribution, i.e., the data requirements are very demanding. Moreover, because the human resource demand is affected by many factors (such as the level of socio-economic development, government policies, production output or sales, expansion plans, management skills, etc.), we must be accurate determine these factors in order to create predictive models. But many human resources-related data can't meet the above requirements. So, it is the primary task for human resource planners to looking for a simple, applicable prediction method which is not required too much data. The grey system prediction method has this characteristics which is less demanding on the amount of data and does not require the typical distribution, so it is an effective prediction method. In recent years, many scholars have used the grey theory to predict the demand of human resource ${ }^{[1-3]}$. However, the traditional $\operatorname{GM}(1,1)$ model is not perfect. Many scholars have studied many improve methods in order to improve

\author{
2. Business School \\ Sichuan University \\ Chengdu, China \\ E-mail: fgmin@cuit.edu.cn
}

the prediction accuracy ${ }^{[4-10]}$. The motivation for the current research is to attempt to propose an improved $\operatorname{GM}(1,1)$ model on the existing basis, named $\operatorname{GM}(1,1)$ model based on the principles of metabolism, and to predict the demand of human resource in real estate industry.

\section{GM(1,1) MODEL BASED ON THE PRINCIPLES OF METABOLISM}

\section{A. Traditional $\operatorname{GM}(1,1)$ Model}

Assume that the original series of data with $n$ entries is

$$
X^{(0)}=\left(x^{(0)}(1), x^{(0)}(2), \cdots, x^{(0)}(n)\right)
$$

where raw material $X^{(0)}$ stands for the non-negative original historical time series data.

Construct $X^{(1)}$ by one time accumulated generating operation (1-AGO), which is

$$
X^{(1)}=\left(x^{(1)}(1), x^{(1)}(2), \cdots, x^{(1)}(n)\right)
$$

Where

$$
x^{(1)}(i)=\sum_{j=1}^{i} x^{(0)}(j)
$$

Define the whitenization differential equation of model $\operatorname{GM}(1,1)$ is ${ }^{[11]}$ :

$$
\frac{d X^{(1)}}{d t}+a X^{(1)}=u
$$

where $a$ is called the development coefficient and represents the development state of the prediction value, $u$ is called the grey action quantity and represents change contained in the data.

Let

$$
B=\left(\begin{array}{cc}
-\frac{1}{2}\left(x^{(1)}(1)+x^{(1)}(2)\right) & 1 \\
-\frac{1}{2}\left(x^{(1)}(2)+x^{(1)}(3)\right) & 1 \\
\ldots & \ldots \\
-\frac{1}{2}\left(x^{(1)}(n-1)+x^{(1)}(n)\right) & 1
\end{array}\right), \quad Y_{N}=\left(\begin{array}{c}
x^{(0)}(2) \\
x^{(0)}(3) \\
\ldots \\
x^{(0)}(n)
\end{array}\right)
$$

If $\beta=(a, u)^{T}$ is the parameter row in Model $\operatorname{GM}(1,1)$, that the least-square state estimation of parameter in model $\operatorname{GM}(1,1)$ is

$$
\beta=\left(B^{\mathrm{T}} B\right)^{-1} B^{T} Y_{N}
$$

Then the general solution of the whitenization differential equation (1) is: 


$$
x^{(1)}(k+1)=-\frac{\mathrm{C}}{a} e^{-a k}+\frac{u}{a}
$$

The particular solution in initial conditions of $x^{(1)}(1)=x^{(0)}(1)$ is:

$$
x^{(1)}(k+1)=\left(x^{(0)}(1)-\frac{u}{a}\right) e^{-a k}+\frac{u}{a}
$$

And inverse accumulating reductive sequence $x^{(0)}$ is

$$
\begin{aligned}
x^{(0)}(k+1) & =x^{(1)}(k+1)-x^{(1)}(k) \\
& =e^{-a k}\left(1-e^{a}\right)\left[x^{(0)}(1)-\frac{u}{a}\right],(k \geq 1)
\end{aligned}
$$

\section{B. Improvement $G M(1,1)$ model}

Improved methods for $\operatorname{GM}(1,1)$ model can be divided into three categories: (1) Improving the method of model parameter estimation; (2) Improving the background value of model; (3) Improving the choose of initial conditions. In this paper, we will improve simultaneously the following two factors: choose of the initial conditions and adjustment of model parameter.

Traditional $\mathrm{GM}(1,1)$ model (4) is a particular solution in the initial conditions of $x^{(1)}(1)=x^{(0)}(1)$, i.e., the curve passes through the first point by using the least squares fitting curve, but this method is lack of theoretical basis. It is not reasonable that the oldest data is the most important. We consider that the newest data is the most important, so we use the initial conditions $x^{(0)}(n)=x^{(0)}(n)$ instead $x^{(1)}(1)=x^{(0)}(1)$, it holds that

$$
\begin{aligned}
x^{(0)}(\mathrm{n}) & =x^{(1)}(\mathrm{n})-x^{(1)}(\mathrm{n}-1) \\
= & \frac{\mathrm{C}}{a} e^{-a(n-1)}\left(e^{a}-1\right)=x^{(0)}(n)
\end{aligned}
$$

So

$$
\frac{\mathrm{C}}{a}=\frac{x^{(0)}(n)}{\left(e^{a}-1\right)} e^{a(n-1)}
$$

Therefore, the special solution of the whitenization differential equation (1) is given by:

$$
x^{(1)}(k+1)=\frac{x^{(0)}(n)}{1-e^{a}} e^{-a(k-n+1)}+\frac{u}{a}
$$

By inverse accumulating reductive sequence $x^{(0)}$, we get the predict model of aboriginal sequence as

$$
x^{(0)}(k+1)=x^{(1)}(k+1)-x^{(1)}(k)
$$

Additional, if we get the parameter $a$ and $u$, traditional GM(1,1) model consider them as constants and use them to predict arbitrary values. It is also unscientific that put things right once and for all. Because the latest data should contain more information than that of the oldest data, it is reasonable that we should put new prediction data into the model, and remove the earliest data, and then adjust the parameter $a$ and $u$, which like as the biological metabolism, we named it as $\operatorname{GM}(1,1)$ model based on the principles of metabolism. i.e., every time when you predict data, you would be required to adjust the values of the parameters $a, u$.

\section{PREDICTION ON HUMAN RESOURCE OF REAL ESTATE}

30 years of reform and opening up, the rapid changes of China's real estate industry is a strong impetus to the development of the national economy and to the improvement of people's living standards. With the increase in the number of real estate, the demand for real estate professionals is also increasing. The macro-demand situation of the real estate industry personnel is affected by many factors, such as: effects of government macroeconomic policy, the level of the real estate industry economic development, social investment in real estate, the market demand on the floor and the owns factors of real estate industry human resources factors(such as the resignation dismissal, retirement etc.). Moreover, among these factors there have little quantifiable information, it can be considered as a gray system. From the data in Table I, the demand of the real estate industry is monotonically increasing trend, and growth in the initial stage of more slowly, then faster and faster, which presents some development trend and suitable for the GM(1,1) model to predict. Research conducted by the People's Republic of China National Bureau of statistics data from 1993 to 2012.

TABLE I. THE HUMAN RESOURCE DEMAND OF REAL ESTATE INDUSTRY UNIT: THOUSAND

\begin{tabular}{|c|c|c|c|c|c|}
\hline Year & Numbers & Year & Numbers & Year & Numbers \\
\hline 1993 & 660 & 2000 & 1000 & 2007 & 1665 \\
\hline 1994 & 740 & 2001 & 1070 & 2008 & 1727 \\
\hline 1995 & 800 & 2002 & 1180 & 2009 & 1909 \\
\hline 1996 & 840 & 2003 & 1202 & 2010 & 2116 \\
\hline 1997 & 870 & 2004 & 1334 & 2011 & 2486 \\
\hline 1998 & 940 & 2005 & 1465 & 2012 & 2737 \\
\hline 1999 & 960 & 2006 & 1539 & & \\
\hline
\end{tabular}

A. Modeling

From Table 1, the aboriginal sequence:

$$
\begin{aligned}
X^{(0)} & =\left(x^{(0)}(1), x^{(0)}(2), \cdots, x^{(0)}(20)\right) \\
& =(66,74,80, \cdots, 248.6,273.7)
\end{aligned}
$$

And the simple accumulating generator sequence of $X^{(1)}$ as

$$
\begin{aligned}
X^{(1)} & =\left(x^{(1)}(1), x^{(1)}(2), \cdots, x^{(1)}(20)\right) \\
& =(66,140,220, \cdots, 2250.4,2824.1) \\
\mathrm{B} & =\left(\begin{array}{cc}
-103 & 1 \\
-180 & 1 \\
\ldots & \ldots \\
-2426.1 & 1 \\
-2687.25 & 1
\end{array}\right) \quad \mathrm{Y}_{N}=\left(\begin{array}{c}
74 \\
80 \\
\ldots \\
248.6 \\
273.7
\end{array}\right)
\end{aligned}
$$

Then, by (2), it holds that

$$
\begin{aligned}
& \beta=(a, u)^{T}=\left(B^{\mathrm{T}} B\right)^{-1} B^{T} Y_{N}=(-0.0726,58.2777)^{T} \\
& \frac{u}{a}=-802.7135 .
\end{aligned}
$$


The development coefficient $a=-0.0726$, which belongs to the effective area of development coefficient $(-2,1)^{[10]}$.

From (7), we get

$$
\begin{array}{r}
x^{(1)}(k+1)=\left(x^{(0)}(20)-\frac{u}{a}\right) e^{-a k}+\frac{u}{a} \\
=1076.4135 e^{0.0726 k}-802.7135
\end{array}
$$

Inverse accumulating reductive sequence $\hat{x}^{(1)}$, we get the predicted model:

$$
x^{(0)}(k+1)=x^{(1)}(k+1)-x^{(1)}(k) .
$$

\section{B. Accuracy test}

\section{1) Error test}

Absolute error is :

$$
\varepsilon^{(0)}(i)=x^{(0)}(i)-x^{(0)}(i)
$$

And relative error is:

\begin{tabular}{|c|c|c|c|c|}
\hline Year & $x^{(0)}(i)$ & $x^{(0)}(i)$ & $\varepsilon^{(0)}(i)$ & $\delta^{(0)}(i)$ \\
\hline 1993 & 660 & 660 & 0 & 0 \\
\hline 1994 & 740 & 740.8 & 0.864 & 0.0012 \\
\hline 1995 & 800 & 796.6 & -3.348 & -0.0042 \\
\hline 1996 & 840 & 856.6 & 16.640 & 0.0198 \\
\hline 1997 & 870 & 921.1 & 51.145 & 0.0588 \\
\hline 1998 & 940 & 990.5 & 50.508 & 0.0537 \\
\hline 1999 & 960 & 1065 & 105.093 & 0.1095 \\
\hline 2000 & 1000 & 1145.2 & 145.295 & 0.1453 \\
\hline 2001 & 1070 & 1231.5 & 161.536 & 0.1510 \\
\hline 2002 & 1180 & 1324.2 & 144.271 & 0.1223 \\
\hline 2003 & 1202 & 1423.9 & 221.989 & 0.1847 \\
\hline 2004 & 1334 & 1535.2 & 201.216 & 0.1508 \\
\hline 2005 & 1465 & 1646.5 & 181.517 & 0.1239 \\
\hline 2006 & 1539 & 1770.5 & 231.501 & 0.1504 \\
\hline 2007 & 1665 & 1903.8 & 238.820 & 0.1434 \\
\hline 2008 & 1727 & 2047.1 & 32.0178 & 0.1854 \\
\hline 2009 & 1909 & 2201.3 & 292.332 & 0.1531 \\
\hline 2010 & 2116 & 2367 & 251.093 & 0.1187 \\
\hline 2011 & 2486 & 2545.3 & 59.335 & 0.0239 \\
\hline 2012 & 2737 & 2737 & 0 & 0 \\
\hline 2013 & 2943.1 & -- & -- & -- \\
\hline
\end{tabular}

$$
\delta^{(0)}(i)=\varepsilon^{(0)}(i) / x^{(0)}(i)
$$

The results are show in the table II.

TABLE II. RESULTS OF RESIDUAL TEST

2) Variance test
Variance test is a special method of gray prediction system test, it through the variance ratio and the small probability of error for testing the model, the model grading criteria as shown in Table III.

Root mean square error of original series $x^{(0)}$ :

$$
S_{0}=\sqrt{\frac{\sum_{i=1}^{20}\left[x^{(0)}(i)-\overline{x^{(0)}}\right]^{2}}{20-1}}
$$

Where

$$
\overline{x^{(0)}}=\frac{1}{20} \sum_{i=1}^{20} x^{(0)}(i)=1362, S_{0}=590.017 \text {. }
$$

Root mean square error of absolute error $\varepsilon^{(0)}$ :

Where

$$
S_{1}=\sqrt{\frac{\sum_{i=1}^{20}\left[\varepsilon^{(0)}(i)-\overline{\varepsilon^{(0)}}\right]^{2}}{20-1}}=0.678
$$

$$
\overline{\varepsilon^{(0)}}=\frac{1}{20} \sum_{i=1}^{20} \varepsilon^{(0)}(i)=0.945 .
$$

Ratio of variance:

$$
C=S_{1} / S_{0}=0.0011 \text {. }
$$

Small error probability:

$$
p=P\left\{\left|\varepsilon^{(0)}(i)-\overline{\varepsilon^{(0)}}\right| \leq 0.6745 S_{0}=397.966\right\} .
$$

From the fourth column of Table II, it holds that

for all, so $\mathrm{p}=1$.

$$
\left|\varepsilon^{(0)}(i)-\overline{\varepsilon^{(0)}}\right| \leq 397.966
$$

TABLE III. PREDICTION ACCURACY RATING SCALE

\begin{tabular}{|l|l|l|}
\hline$p$ & $C$ & Prediction precision grade \\
\hline$>0.95$ & $<0.35$ & 1 (Excellent) \\
\hline$>0.80$ & $<0.5$ & 2 (Qualified) \\
\hline$>0.70$ & $<0.65$ & 3 (Reluctantly qualified) \\
\hline$\leq 0.70$ & $\geq 0.65$ & 4 (poor) \\
\hline \multicolumn{2}{|l|}{$C=0.0011<0.35, \quad p=1>0.95$. Prediction precision }
\end{tabular}

grade of model is 1 (Excellent), so we can use the model (8) to predict the human resources of real estate industry in 2013.

\section{3) Prediction and analysis}

From (8), the human resources of real estate industry in 2013 is 2943.1 thousands. By GM(1,1) model based on the principles of metabolism, the values of the parameters is adjusted as :

$$
(a, u)^{T}=(-0.0795,57.6287)^{T}
$$

So the demand for human resources of real estate industry in 2014 is about 3186.5 thousands.

Similarly, the values of the parameters is adjusted as $(a, u)^{T}=(-0.0781,69.5139)^{T}$,

So the demand for human resources of real estate industry in 2015 is about 3445 thousands.

From 2013 to 2015, the real estate demand will increase about 200000 people annually, which means that estate professional's demand has increased steadily. It is shown, according to relevant data, that China's real estate 
is still in the development period in 2013, 2014. Compared with 2012, the national real estate development and investment growth rate increased $6.6 \%$ in 2013, and from January to September, the national real estate development investment reached 6.112 trillion yuan, a year-on-year growth of $19.7 \%$. In 2013 the national real estate investment growth rate is more than $30 \%$, the restart area, the completion area and sales area is synchronous growth. This year (2014) of the national real estate investment growth is still large. An increase in the expansion of the scale will inevitably lead to increase in human resources. In addition, the real estate practitioners' pay, from the growth point of view, is one of the highest and fastest ones, this is also another reasons for large growth of real estate practitioners.

However, it should be noted that the real estate market demand for human resources improve both the quantity and the quality, it has developed from quantitative to qualitative. Today's real estate market has transform from product marketing to brand marketing transition, and the consumer has become more mature and rational, they have higher requirements for apartment, the environment and property management etc.. Thus, the quality requirements for real estate practitioners also increased accordingly. In China, the real estate industry is still in its infancy, a relatively short history, there are many problems to be solved, and human resource management has not been given due attention. Many real estate companies lack development training, rational use of human resources, and effective incentive concept of talent. Therefore, the real estate enterprises to healthy development, we must change the idea as soon as possible, establish a "people-oriented" management concept, pay attention to the importance and value of human resources in the development of enterprises, let the ability and potential to effectively play out. Only in this way, can we make the enterprise in an invincible position in the competition.

\section{CONCLUSION}

In this paper, we propose improved $\operatorname{GM}(1,1)$ model based on the principle of metabolic, and use it to predict the human resources macro demand in the real estate industry in 2013-2015. Due to gray $\operatorname{GM}(1,1)$ prediction model theoretical simple, convenient operation, it has been widely used in many fields. Gray prediction theory is very effective for some sectors of human resources demand forecasting, especially macroeconomic forecasting demand. Gray prediction theory developed very mature, there are many ways to improve the prediction accuracy, so it is desirable for the prediction of human resources. Meanwhile, we should also see that although $\operatorname{GM}(1,1)$ model can predict future staffing needs at any moment in theory, but it is better in the short-term prediction than long-term prediction, because as time goes on, some of the disturbance factors will enter the system, affect its long-term forecast accuracy. On the other hand, the growth of human resources demand is impossible unlimited, it is limited by the number of populations, the scarcity of land resources and the government's macrocontrol, it is necessary to adjust the predicted results.

\section{ACKNOWLEDGMENT}

This work is supported by scientific research foundation of the education department of Sichuan province (14ZB0173).

\section{REFERENCES}

[1] Jiang Ronghua, Cao Qi. The human resources demand prediction of the enterprise based on grey BP neural network [J]. Human Resource Development of China, 2011,11:42-46.

[2] Li Xiaobang. The human resources of university logistics demand forecasting based on Grey Model [J]. Human resource management, 2012, 11:160-161

[3] ZHOU Yong-hua, LIU Yan, SU Yong-jie. A Forecasting Analysis of Human Resource Demand in Xinjiang Based on GM(1,1) Model [J]. Journal of Xinjiang University (Philosophy, Humanities and Social Sciences). 2013,41(4):25-29.

[4] Huang Changjun, Tang Zhengqi, Zhou Qingshan, Cao Yuanzhi. Application of Improved Error GM $(1,1)$ Model on Predicting of Cultivated Land in Yiyang [J]. Energy Procedia, 2011, 5: 1172 1176.

[5] WANG Zheng-xin, DANG Yao-guo, LIU Si-feng. Optimization of Background Value in GM(1,1) Model [J]. Systems Engineering — Theory \& Practice, 2008, 28(2): 61-67.

[6] DANG Yao-guo, LIU Si feng, LIU Bin. The GM Models that $x(n)$ be Taken as Initial Value $[\mathrm{J}]$. Chinese Journal of Management Science, 2005, 13(1):132 - 134.

[7] Deng Ju Long. Solution of Grey Differential Equation for $G M(1,1 \mid \pi, \mathrm{r})$ in Matrix Train [J]. The Journal of Grey System, 2002, 14(1): 105-110.

[8] Chun-I Chen, Shou-Jen Huang. The necessary and sufficient condition for $\mathrm{GM}(1,1)$ grey prediction model [J]. Applied Mathematics and Computation, 2013, 219: 6152-6162.

[9] Zheng-Xin Wang, Yao-Guo Dang, Si-Feng Liu, Jing Zhou. The Optimization of Background Value in $\operatorname{GM}(1,1)$ model $[\mathrm{J}]$. Journal of Grey System, 2007, 10(2):69-74.

[10] Wu Tiankui, Wang Bo, Zhou Xiaohui, Zhao Yini. An Improved Grey GM(1,1) Model for Prediction of Fire Losses [J]. Mathematical theory and applications, 2014, 34(1):59-70.

[11] Deng Julong. Basic method of grey system [M]. Hua zhong Institute of Technology Press, 1998.

[12] LI Qun, CHEN Wei. A note for the Range suitable for $\operatorname{GM}(1,1)[\mathrm{J}]$ Mathematic in practice and theory. 2002, 32(3):443-444. 